\title{
Original article (short paper) \\ Vastus lateralis muscle architecture to estimate knee extension moment of older individuals
}

\author{
Guilherme Auler Brodt \\ Universidade de Caxias do Sul, Caxias do Sul, Brazil \\ Jeam Marcel Geremia \\ Universidade Federal do Rio Grande do Sul, Porto Alegre, Brazil \\ Mônica de Oliveira Melo \\ Universidade de Caxias do Sul, Caxias do Sul, Brazil \\ Marco Aurélio Vaz \\ Jefferson Fagundes Loss \\ Universidade Federal do Rio Grande do Sul, Porto Alegre, Brazil
}

\begin{abstract}
The aim of this study was to compare the knee extension moment of older individuals with the muscle moment estimated through a biomechanical model. This was accomplished by using (1) the specific muscle architecture data of individuals, and (2) the generic muscle architecture available in the literature. The muscle force estimate was determined using a model with the muscle architecture from cadavers and the individual vastus lateralis muscle architecture of sixteen older volunteers. For the muscle moment comparison, all of the volunteers performed maximal voluntary isometric contractions (MVIC) in five different knee extension position angles. The architectural data was acquired using both resonance and ultrasound imaging. Both estimated muscle moments (generic and individual) were higher than the experimental. The architecture of the other vastii may be necessary to make the model more accurate for the older population. Although other factors inherent to ageing, such as co-contractions, fiber type percentage, and passive forces are not considered in the model, they could be responsible for the differences between moments in older people.
\end{abstract}

Keywords: muscle architecture, muscle model, older individuals, moment

Resumo - "Arquitetura do músculo vasto lateral para estimar o momento de extensão do joelho de indivíduos idosos." O objetivo deste estudo foi comparar o momento de extensão do joelho de idosos com momento muscular estimado por modelo biomecânico, utilizando (i) arquitetura muscular específica dos indivíduos e (II) arquitetura muscular genérica disponível na literatura. Para a estimativa da força muscular foi utilizado um modelo com a arquitetura muscular de cadáveres, e também com a arquitetura do vasto lateral de dezesseis voluntários idosos. Para a comparação todos voluntários realizaram contrações isométricas voluntárias máximas em cinco ângulos. Os dados de arquitetura foram adquiridos por meio de ultrassonografia e por ressonância magnética. Ambos os momentos estimados (genéricos e individuais) foram maiores do que experimental. A arquitetura dos outros músculos do quadríceps pode ser necessária para modelo ser mais preciso para a população idosa. Outros fatores inerentes ao envelhecimento não foram considerados no modelo, como cocontrações, tipagem de fibras e forças passivas, e devem ser responsáveis pelas diferenças entre os momentos.

Palavras-chave: arquitetura muscular, modelo muscular, idosos, momento muscular

Resumen - "Arquitectura de los vasto lateral para estimar el momento de la extensión de la rodilla de las personas ancianas." El objetivo de este estudio fue comparar el torque extensión de la rodilla de ancianos con torque muscular estimado por modelo biomecánico, usando (i) la arquitectura muscular específica de los individuos y (II) (II) la arquitectura muscular genérica disponible en la literatura. Para la estimación de la fuerza muscular se utilizó un modelo con arquitectura muscular de cadáveres, y también con la arquitectura del vasto lateral de dieciséis voluntarios ancianos. Para la comparación todos los voluntarios realizaron contracciones isométricas voluntarias máximas en cinco ángulos. La arquitectura fue adquirida por ecografía y por resonancia magnética. Ambos las torques estimadas (genéricas y individuales) fueron mayores que el experimental. La arquitectura de los otros músculos de los cuádriceps puede ser necesaria para hacer el modelo más preciso para la población anciana. Otros factores inherentes envejecimiento no se consideran en el modelo, como co-contracciones, el tipo de fibra y fuerzas pasivas, y deben ser responsables de las diferencias entre las torques.

Palabras claves: arquitectura muscular, modelo muscular, ancianos, momento muscular 


\section{Introduction}

Mechanical changes in muscle force production during aging have been documented. Compared to young adults, healthy older adults show a substantial loss of muscle strength (Akima et al., 2001; Frontera, 2006; Narici, Maffulli, \& Maganaris, 2008), a decrease in muscle thickness, and a shortening of fascicle muscle length (Baroni et al., 2013; Kubo et al., 2003). These gradual changes can directly affect how older people perform the activities of daily living. In addition, such changes can also affect functional tasks, such as walking, and increase the number of falls (Iezzoni, McCarthy, Davis, \& Siebens, 2001). Precise knowledge of muscle function is necessary to slow this significant loss of functional abilities. A common method for understanding muscle function is to measure the muscle force or its moment generation capacity (i.e., muscle moment). In addition to directly measuring the muscle, the muscle moment can be estimated by muscle models, such as the Hill-based muscle models (Thelen, 2003).

Several Hill-based computational models were created to analyze the muscle function of lower limbs (Blemker \& Delp, 2006; Lloyd \& Besier, 2003; Neptune, Kautz, \& Zajac, 2001). Most of these models have a common limitation since they use the generic muscle architecture parameters reported in the literature to estimate muscle forces, such as to employ the average muscle architecture values collected from cadavers, ignoring the individual muscle architecture of the studied population, such as the older population (Pandy \& Andriacchi, 2010). When used as parameters for it, the muscle architecture is capable of significantly changing the muscle model estimation of muscle force as well as that of the joint movements (Brand, Pedersen, \& Friederich, 1986; Raikova \& Prilutsky, 2001; Redl, Gfoehler, \& Pandy, 2007; Scovil \& Ronsky, 2006; Thelen, 2003). It is possible that the models (Arnold, et al., 2010; Delp et al., 1990) that were previously developed and validated for the estimation of muscle moment in young adults (Thelen, 2003) incorrectly estimate the muscle moment produced by older people.

Although biomechanical models have been widely employed for the evaluation of muscle function and muscle moment production in young subjects, its applicability to the older population is still uncertain. Since young adults tend to produce more force than older people do, these models would overestimate the force of the older individuals. The practical consequence of this error is that the diagnosis of muscle that is affecting a particular activity may be wrong. Furthermore, since older individuals present significant alterations in their muscle architecture, which leads them to produce less muscle force, it is natural to infer that generic models with a muscle architecture based in young adults may not be accurate (Narici, Maganaris, Reeves, \& Capodaglio, 2003; Narici, Reeves, Morse, \& Maganaris, 2004; Sipila \& Suominen, 1991).

The use of muscle architecture specifically from older individuals would be beneficial to the estimation. On the other hand, the measurement of specific parameters for each individual is associated with a high cost, both because of the necessary technologies, such as imaging (ultrasound or magnetic resonance imaging, for example), and the time needed for these tests
(Jacobson, 2002). Since the architecture of the vastus lateralis muscle is typically analyzed in the older population (Baroni et al., 2013; Melo et al. 2014), it is possible that this architecture could enhance the joint moment estimation of the model. This one muscle architecture could make models to be more precise with less effort compared, for example, to acquiring the entire architecture of the whole quadriceps muscle. Therefore, it is not clear whether the effort to measure the muscle architecture is advantageous to the model responses; moreover, the models have limitations in their estimates and direct measurements of these parameters are susceptible to error.

Consequently, the aim of this study was to compare the acquired muscle moment of older people with the muscle moment estimated for the lower limbs via biomechanical model. The calculation parameters of muscle force were (1) the specific muscle architecture data of individuals and (2) the generic muscle architecture available in the literature. We speculated that the estimate using the individual specific muscle architecture more accurately represents the effective moment achieved by older individuals and the general muscular architecture overestimates the experimental muscle moment.

\section{Methods}

The sample data of this study are the muscular architecture of the vastus lateralis muscle of sixteen older volunteers (59.1 \pm 8 years, mass $79.5 \pm 16 \mathrm{~kg}$, and height $156.0 \pm 7 \mathrm{~cm}$ ) of both sexes and without osteoarticular disease in the lower limbs and joints. The Biomechanics and Kinesiology Research Group of the Exercise Research Laboratory of the Federal University of Rio Grande do Sul provided the architecture data. In this study, the model utilized for the individual estimated muscle moment was published by Delp et al. (1990) and adapted by Arnold (2010). A dynamic model consists of the rigid body of the phalanges, metatarsals, calcaneus, talus, fibula, tibia, patella, femur, and pelvis. The joints represented in the model include the metatarsophalangeal, subtalar, ankle, knee, and hip joints. The model includes 35 Hill-type muscle models (Zajac, 1989) of the lower limbs, which are based on the muscular architecture data from 21 cadavers (Ward et al., 2009). This model requires four parameters for each of the Hill-type muscle models (optimal fiber length, maximum isometric force, pennation angle, and tendon slack length) to scale generic curves for active and passive force generation (Arnold et al., 2010; Delp, 1990). To individualize the muscle models for each of the participants, we used the in vivo muscle architecture of the vastus lateralis and kept the other quadriceps muscles with the generic muscle architecture.

The maximum isometric joint moment of a muscle is the product of its maximum isometric force (Zajac, 1989) and its moment arm. The maximum isometric joint moment that a muscle can generate (or just muscle moment) was estimated using a scaled model individualized for each subject. The maximum isometric muscle force was calculated from the measured architectural values of the physiological cross-section area from each individual and a specific tension of $61 \mathrm{~N} / \mathrm{cm}^{2}$ for 
all muscles (Arnold et al., 2010; Delp, 1990). The maximum isometric joint moments were calculated as a function of knee angle by summing the moments generated by all muscles that could contribute to the joint moment over the knee ROM.

To individualize the model for the maximum isometric force and the moment arm of each subject, the models were scaled using anatomical properties (limb length) for the moment arm and the muscle architecture (optimal fascicle length, pennation angle, and physiological cross sectional area) of the vastus lateralis muscle for passive force and active length curve. The pennation angles and fascicle lengths were collected via ultrasound (Table 1). The in vivo muscle architecture (vastus lateralis pennation angle and fascicle length) data was obtained using ultra-sonography (ALOKA SSD 4000) with the subjects seated in an at rest position. Subjects had their vastus lateralis anatomic cross sectional area measured by magnetic resonance image (MRI; Siemens Magnetom Visio Plus) of axial T2-weighted scans of the thigh obtained at 16-m intervals from the superior border of the patella to the greater trochanter (slice thickness $=$ $4 \mathrm{~mm}$ ). From these scans, an anatomic cross sectional area was measured for each slice by manually tracing the perimeter of VL with ImageJ 1.41 (National Institute of Health, USA). The product of the cross-sectional area and the slice thickness of all images were added to calculate the volume of the vastus lateralis.

For the physiological cross section area estimation, Morse's regression equation (Morse, Degens, \& Jones, 2007) was used with the anatomic cross section area acquired by magnetic resonance imaging in previous studies (de Oliveira \& Luporini Menegaldo, 2010; Menegaldo \& Oliveira, 2009; Nam \& Uhm, 2011). The optimal fascicle length was acquired via linear regression between optimal fiber length and the mean sarcomere length in the evaluated position, and assuming mean length sarcomere as $2.7 \mu \mathrm{m}$, as described by Ward et al. (2009).

After estimating the maximum isometric muscle moment with the architectural parameters collected from each individual, it was estimated again using the generic architecture of the values reported by Ward et al. (2009) for all quadriceps muscles. This will be considered as those proposed by the literature in the course of this article and that are already commonly used in the model of Arnold et al. (2010).

To acquire the experimental muscle moment, each volunteer performed the maximal voluntary isometric contractions (MVIC) of the knee extensors in a Biodex System 3 Dynamometer, measure error inferior to $1 \%$ (Zawadzki, Bober, \& Siemienski, 2010). Prior to the MVIC, a five-minute warm-up in a cycle ergometer and twelve knee extensions in the isokinetic dynamometer, both without load, were completed. After familiarization and warm-up, two MVICs were performed randomly in each angle of knee flexion $\left(30^{\circ}, 45^{\circ}\right.$, $60^{\circ}, 75^{\circ}$, and $90^{\circ}$ ). Two minutes of rest were taken between each MVIC to avoid possible fatigue effects. For comparison, we used the highest knee extension muscle moment of each evaluated angle. The MVIC estimates were obtained from a scaled model for each volunteer.

Therefore, as a result of the above procedures, we have three maximum isometric muscle moment variables. They are named as follows: (1) The experimental muscle moment, which is the moment obtained by isokinetic dynamometer. (2) The individual estimated muscle moment, which is the moment estimated using the vastus lateralis muscle architecture of the individual volunteers. And (3) the generic estimated muscle moment, which is the moment estimated by the generic architecture model with Ward et al. (2009) muscle architecture, without any kind of model individualization. Ethical approval for this study was obtained in accordance with resolution 466 of the 2012 Brazilian National Health Council (number 21740, April 24, 2012).

Table 1. Individual parameters of femur length (for scaling), physiological cross-sectional area (PCSA), pennation angle (PA), and fascicle length (FL) of the vastus lateralis muscle of this study and those presented by Ward et al. (2009) and used in the model of the lower limbs Delp et al. (1990) as adapted by Arnold (2010).

\begin{tabular}{|c|c|c|c|c|}
\hline \multirow[t]{2}{*}{ Sample } & \multirow{2}{*}{$\begin{array}{l}\text { Femur Length } \\
(\text { (cm) }\end{array}$} & $\begin{array}{l}\text { PCSA } \\
\left(\mathrm{cm}^{2}\right)\end{array}$ & $\begin{array}{c}\text { PA } \\
\text { (degrees) }\end{array}$ & $\begin{array}{c}\mathrm{FL} \\
(\mathrm{cm})\end{array}$ \\
\hline & & VL & VL & VL \\
\hline 1 & 44.8 & 33.6 & 10.4 & 9.2 \\
\hline 2 & 44.4 & 42.3 & 9.0 & 7.9 \\
\hline 3 & 44.3 & 30.1 & 9.0 & 14.2 \\
\hline 4 & 43.9 & 39.7 & 13.8 & 8.9 \\
\hline 5 & 44.6 & 44.3 & 12.7 & 8.4 \\
\hline 6 & 44.6 & 50.6 & 12.7 & 8.4 \\
\hline 7 & 44.3 & 49.3 & 9.4 & 13.3 \\
\hline 8 & 42.8 & 35.7 & 7.2 & 13.4 \\
\hline 9 & 44.5 & 49.1 & 9.3 & 10.7 \\
\hline 10 & 44.3 & 27.1 & 10.6 & 10.8 \\
\hline 11 & 45.5 & 25.2 & 8.7 & 14.9 \\
\hline 12 & 40.4 & 30.2 & 7.1 & 14.3 \\
\hline 13 & 44.6 & 48.4 & 9.0 & 7.8 \\
\hline 14 & 44.3 & 24.9 & 9.3 & 10.0 \\
\hline 15 & 44.3 & 32.1 & 13.2 & 9.8 \\
\hline 16 & 47.5 & 35.2 & 7.2 & 12.0 \\
\hline Average & 44.3 & 37.4 & 9.9 & 10.9 \\
\hline$\pm \mathrm{SD}$ & \pm 1.4 & \pm 9.0 & \pm 2.2 & \pm 2.5 \\
\hline Ward et al. & 45 & 35.1 & 18.4 & 9.9 \\
\hline
\end{tabular}

\section{Statistical analysis}

The individual estimated muscle moment and the generic estimated muscle moment were compared to the experimental muscle moment using repeated-measures ANOVA. In the first step, the sphericity of the muscle moment data for each angle was assessed with a Mauchly's test. Green House-Geisser estimates were reported when the assumption of sphericity was violated. If differences were found, a second step was performed in which each angle within the subjects was compared using a Bonferroni correction. The significance level was $p<.05$ for all tests. These analyses were performed using IBM SPSS Statistics software (Version 20.0; IBM, Tokyo, Japan). The agreement 
between the estimated muscle moments (generic and individual) and the experimental muscle moment was assessed using Bland and Altman's (1986) graphical analysis technique.

\section{Results}

There was a significant main effect for the estimation method in all analyzed angles: $90^{\circ}\left(F_{13,3}=10.843, p<.01\right)$, $75^{\circ}\left(F_{13,3}=12.464, p<.01\right), 60^{\circ}\left(F_{13,3}=12.117, p<.01\right)$, $45^{\circ}\left(F_{13,3}=38.359, p<.01\right)$ and $30^{\circ}\left(F_{13,3}=58.613, p<.01\right)$, sphericity was not assumed just for $75^{\circ}$. As result of post hoc, both estimated muscle moments (generic and individual) were higher than the experimental (Figure 1), except for $90^{\circ}$, where the individual estimated muscle moment was not different from the experimental muscle moment. By the Bland and Altman agreement assessment, the average difference between the generic estimated moment and the experimental muscle moment was $-48.4 \mathrm{Nm}( \pm 31.8 \mathrm{Nm})$. It is possible to note a clear increasing shape pattern in the data dispersion, specifically, the lower the muscle moment, the greater the difference between the experimental muscle moment and the generic estimated muscle moment (Figure 2). The data are not uniformly distributed because we did not make any individualization on the estimation of the models; therefore, the results tend to be the same for multiple subjects. The average difference between the individual estimated muscle moment and the experimental muscle moment was $-63.2 \mathrm{Nm}$ $( \pm 49.2 \mathrm{Nm})$ (Figure 3$)$. One can see a random pattern in the data dispersion.

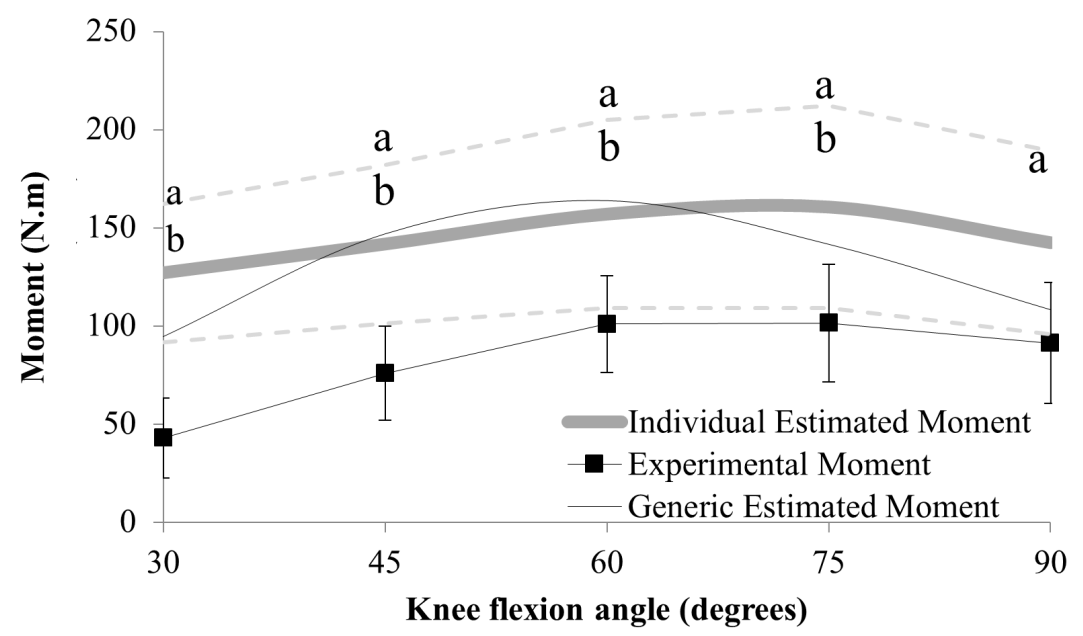

Figure 1. Experimental and estimated moment results. Dashed lines indicate the standard deviation of the individual estimated moment: a. indicates the difference $(p<.05)$ between the individual estimated and the experimental moment, and $\mathbf{b}$. indicates the difference $(p<.05)$ between the generic estimated and the experimental moment.

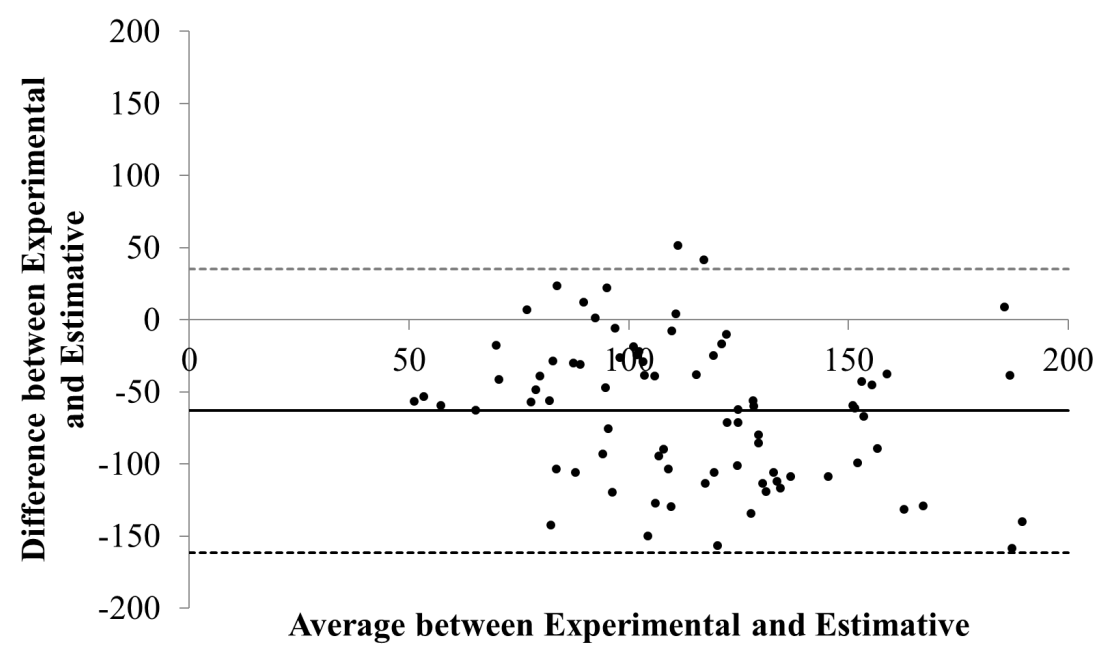

Figure 2. Bland and Altman agreement between experimental and generic estimated moment results. The dark line represents the average difference between the techniques. The dashed lines represent the $95 \%$ confidence interval. 


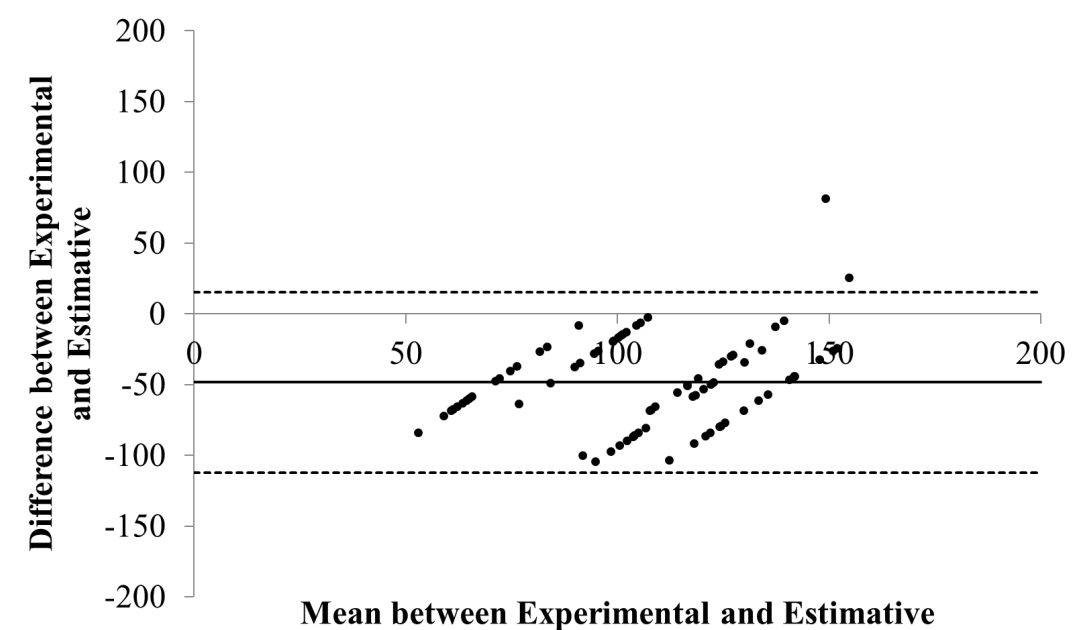

Figure 3. Bland and Altman agreement between experimental and individual estimated moment results. The dark line represents the average difference between the techniques. The dashed lines represent the $95 \%$ confidence interval.

\section{Discussion}

The results of the present study show that, regardless of the evaluated angle of the knee extension, estimating the muscle moment using generic muscle architecture or individual muscle architecture as parameters for the model leads to an overestimation of the experimental muscle moment performed by the older individuals. A feasible reason that the older individuals have produced less moment may be the fact that this population has a reduced muscle moment production capacity compared to young adults (Pääsuke, Ereline, \& Gapeyeva, 2003). However, since the parameters of the muscle architecture used to individualize the muscle model are considered good predictors of muscle force in adults (Buchanan, Lloyd, Manal, \& Besier, 2004; de Oliveira \& Luporini Menegaldo, 2010), its inconsistency in muscle moment calculation is probably because of other limitations of the model.

Some limitations inherent to biomechanical muscle models of this nature must be noted. Muscle models such as these do not consider passive forces, such as joint stiffness or antagonist muscle shortening, which may present difficulty with the knee extension during the evaluation. In addition, the process of muscle atrophy and hypoplasia, known as the sarcopenia process, can affect the muscle structure and cause differences in the muscle recruitment patterns in older individuals (Chesworth \& Vandervoort, 1989; Narici, Maganaris, Reeves, \& Capodaglio, 2003). Although all of these processes can affect muscle force production, the model predicts none of them.

Specifically, older people have high rates of co-activation during vigorous contractions (de Boer, Morse, Thom, de Haan, \& Narici, 2007; Pereira \& Gonçalves, 2011). It is important to notice this co-activation because is configured as simultaneous activation of muscles moving a given joint (Hortobágyi et al., 2005). In the case of the knee, the hamstrings are an important group that may counteract the force exerted by the quadriceps muscles and can significantly decrease the maximum isometric torque exerted by the older volunteers.
Another factor of recurrent sarcopenia is the reduction of type II fibers specifically (Andersen, 2003; Coggan et al., 1992; Lexell, Henriksson Larsen, \& Winblad, 1983). These fibers are responsible for fast strong contractions and a significant decrease compared to type I fibers. This decrease may be responsible for a smaller force per unit area exerted by the muscles in the older population (Narici \& Maffulli, 2010), a reduction in the tension $\left(\mathrm{N} / \mathrm{cm}^{2}\right)$ of the muscle. With a lower concentration of type II fibers, it is natural that the muscle produces less force per unit area, thus causing overestimations in the muscle model calculations.

In health sciences, it is customary to compare new measurement techniques with established measurement techniques to determine whether the new techniques agree sufficiently to be correlated with/or to even replace the established measurement techniques (Bland \& Altman, 1986, 1995). Assessing the graphics according to the recommendations of Bland and Altman (1986 and 1995), it is clear that both techniques (individual estimated muscle moment and generic estimated muscle moment) used to estimate the experimental muscle moment have predominantly negative average differences. Therefore, the simulation overestimated the moment produced by the older individuals. Additionally, the individual estimated muscle moment had higher average differences compared to the muscle moment obtained using generic parameters.

Including the individual muscle architecture of the vastus lateralis (individual estimated muscle moment) had a greater confidence interval (distance between the +2 sds and -2 sds lines) than the calculation using generic muscle architecture. The individual estimated muscle moment and the generic estimated muscle moment had confidence interval values of $197.0 \mathrm{Nm}$ and $127.3 \mathrm{Nm}$ respectively. These values represent a great variance in the simulations since the mean difference between young adults and the older individuals is approximately $100 \mathrm{Nm}$ (Baroni et al., 2013). Blazevich et al. (2009) compared the coefficient of determination $\left(R^{2}\right)$ 
for the estimation of muscle moment with the individual muscle architecture and found a strong relationship $\left(R^{2}=\right.$ .7) when using a muscle cross section area. The authors do not show agreement analyses on their study; however, they could be useful for further consideration (Bland \& Altman, 1986, 1995).

Despite the fact that the generic estimated muscle moment graphical analyses presented a smaller variation, looking at the slope behavior, you can see that it has an upward trend. However, according to Bland and Altman (1995), a high correlation with the upward behavior indicates a biased error. On the other hand, the individual estimated muscle moment has a random error, which avoids biased inferences.

Another factor that cannot be ignored is the errors that are characteristic to the experimental muscle moment measure due to coactivation and protocol positioning problems. Older individuals can reach up to $40 \%$ of their maximum voluntary contraction of antagonist muscles (knee flexors) during maximum knee extension tests (Macaluso et al., 2002). Although we did not measure the muscle moment of the knee flexors, according to Macaluso et al. (2002), they can reach 34.6 N.m of the knee flexor's maximum muscle moment. Therefore, the effect of the coactivation of the knee flexors during knee extension is a counterforce of nearly 30 N.m. This antagonist muscle moment generation could represent more than $30 \%$ of the total knee extension muscle moment, done by the subjects of our study, just to oppose the knee flexor's moment. An extra 30\% muscle moment done by knee extensors could be enough for the model to estimate the experimental muscle moment correctly. Thus, we presume that this could be the main source of error in our estimations. Misalignment of the dynamometer and the joint axis, which can generate an error range between $1.9 \%$ and $4.3 \%$, are other measurement errors that can influence the results (Tsaopoulo et al., 2011). To minimize this source of error, we are diligent in ensuring that the alignment between the knee and the dynamometer are as optimal as possible during the protocol.

Both estimates were higher than the experimental muscle moment, partially agreeing with the initial hypothesis of the study. The architecture of the other vastii may be necessary to make the model more accurate for the older population. Nevertheless, even with more muscles, other factors not considered in the model, such as co-contractions, fiber type percentage, and passive forces, could be responsible for the differences between the experimental and the estimated muscle moments.

\section{Conclusion}

The vastus lateralis architecture did not improve the model's knee extension moment estimate satisfactorily in the older population. Despite the fact that the architecture changed the error dispersion pattern, the individual estimated muscle moment still presented a low correlation and high average error related to the experimental muscle moment.

\section{References}

Akima, H., Kano, Y., Enomoto, Y., Ishizu, M., Okada, M., Oishi, Y., ... Kuno, S.Y. (2001). Muscle function in 164 men and women aged 20-84 yr. Medicine and Science in Sports and Exercise, 33, 220-226.

Andersen, J.L. (2003). Muscle fibre type adaptation in the elderly human muscle. Scandinavian Journal of Medicine and Science in Sports, 13, 40-47.

Arnold, E.M., Ward, S.R., Lieber, R.L., \& Delp, S.L. (2010). A model of the lower limb for analysis of human movement. Annals of biomedical engineering, 38, 269-279.

Baroni, B.M., Geremia, J.M., Rodrigues, R., Borges, M.K., Jinha, A., Herzog, W., \& Vaz, M.A. (2013). Functional and morphological adaptations to aging in knee extensor muscles of physically active men. J Appl Biomech, 29, 535-542.

Bland, J.M., \& Altman, D.G. (1986). Statistical methods for assessing agreement between two methods of clinical measurement. Lancet, $1,307-310$.

Bland, J.M., \& Altman, D.G. (1995). Comparing methods of measurement: Why plotting difference against standard method is misleading. Lancet, 346, 1085-1087.

Blazevich, A.J., Coleman, D.R., Horne, S., \& Cannavan, D. (2009). Anatomical predictors of maximum isometric and concentric knee extensor moment. European Journal of Applied Physiology, 105, 869-878.

Blemker, S.S., \& Delp, S.L. (2006). Rectus femoris and vastus intermedius fiber excursions predicted by three-dimensional muscle models. Journal of biomechanics, 39, 1383-1391.

Brand, R.A., Pedersen, D.R., \& Friederich, J.A. (1986). The sensitivity of muscle force predictions to changes in physiologic cross-sectional area. Journal of biomechanics, 19, 589-596.

Buchanan, T.S., Lloyd, D.G., Manal, K., \& Besier, T.F. (2004). Neuromusculoskeletal modeling: Estimation of muscle forces and joint moments and movements from measurements of neural command. Journal of Applied Biomechanics, 20, 367-395.

Chesworth, B.M., \& Vandervoort, A.A. (1989). Age and passive ankle stiffness in healthy women. Physical Therapy, 69, 217-224.

Coggan, A.R., Spina, R.J., King, D.S., Rogers, M.A., Brown, M., Nemeth, P.M., \& Holloszy, J.O. (1992). Histochemical and enzymatic comparison of the gastrocnemius muscle of young and elderly men and women. Journals of Gerontology, 47, B71-B76.

de Boer, M.D., Morse, C.I., Thom, J.M., de Haan, A., \& Narici, M.V. (2007). Changes in antagonist muscles' coactivation in response to strength training in older women. J Gerontol A Biol Sci Med Sci, 62, 1022-1027.

de Oliveira, L.F., \& Luporini Menegaldo, L. (2010). Individual-specific muscle maximum force estimation using ultrasound for ankle joint torque prediction using an EMG-driven Hill-type model. Journal of biomechanics, 43, 2816-2821.

Delp, S., Loan, J., Hoy, M., Zajac, F., Topp, E., Rosen, J. (1990). An interactive graphics-based model of the lower extremity to study orthopaedic surgical procedures. IEEE Transactions on Biomedical Engineering, 37, 757-767.

Frontera, W.R. (2006). Aging muscle. Critical Reviews in Physical and Rehabilitation Medicine, 18, 63-93. 
Hortobágyi, T., Westerkamp, L., Beam, S., Moody, J., Garry, J., Holbert, D., \& DeVita, P. (2005). Altered hamstring-quadriceps muscle balance in patients with knee osteoarthritis. Clinical Biomechanics, 20, 97-104.

Iezzoni, L.I., McCarthy, E.P., Davis, R.B., \& Siebens, H. (2001). Mobility difficulties are not only a problem of old age. Journal of General Internal Medicine, 16(4), 235-243.

Kubo, K., Kanehisa, H., Azuma, K., Ishizu, M., Kuno, S. Y., Okada, M., \& Fukunaga, T. (2003). Muscle architectural characteristics in young and elderly men and women. International Journal of Sports Medicine, 24, 125-130. doi: 10.1055/s-2003-38204

Lexell, J., Henriksson Larsen, K., \& Winblad, B. (1983). Distribution of different fiber types in human skeletal muscles: Effects of aging studied in whole muscle cross sections. Muscle and Nerve, 6(8), 588-595.

Lloyd, D.G., \& Besier, T.F. (2003). An EMG-driven musculoskeletal model to estimate muscle forces and knee joint moments in vivo. Journal of biomechanics, 36, 765-776.

Macaluso, A., Nimmo, M.A., Foster, J.E., Cockburn, M., McMillan, N.C., \& De Vito, G. (2002). Contractile muscle volume and agonist-antagonist coactivation account for differences in torque between young and older women. Muscle \& Nerve, 25, 858-863. doi: 10.1002/mus. 10113

Melo, M.D., Pompeo, K.D., Brodt, G.A., Baroni, B.M., da Silva Junior, D.P., \& Vaz, M.A. (2014). Effects of neuromuscular electrical stimulation and low-level laser therapy on the muscle architecture and functional capacity in elderly patients with knee osteoarthritis: a randomized controlled trial. Clinical Rehabilitation. 29, 570-80. doi: 10.1177/0269215514552082

Menegaldo, L.L., \& Oliveira, L.F.d. (2009). Effect of muscle model parameter scaling for isometric plantar flexion torque prediction. Journal of biomechanics, 42(15), 2597-2601.

Morse, C.I., Degens, H., \& Jones, D.A. (2007). The validity of estimating quadriceps volume from single MRI cross-sections in young men. European Journal of Applied Physiology, 100, 267-274.

Nam, Y., \& Uhm, H.W. (2011). Tendon slack length and its effect on muscle force-generation characteristics. Journal of Mechanics in Medicine and Biology, 11, 445-456. doi: 10.1142/ s0219519410003770

Narici, M.V., \& Maffulli, N. (2010). Sarcopenia: Characteristics, mechanisms and functional significance. British Medical Bulletin, 95, 139-159.

Narici, M.V., Maffulli, N., \& Maganaris, C.N. (2008). Ageing of human muscles and tendons. Disability and Rehabilitation, 30(20-22), 1548-1554. doi: 10.1080/09638280701831058

Narici, M.V., Maganaris, C.N., Reeves, N.D., \& Capodaglio, P. (2003). Effect of aging on human muscle architecture. Jourrnal of Applied Physiology, 95, 2229-2234. doi: 10.1152/japplphysiol.00433.2003

Narici, M.V., Reeves, N.D., Morse, C.I., \& Maganaris, C.N. (2004). Muscular adaptations to resistance exercise in the elderly. Journal of Musculoskeletal Neuronal Interactions, 4, 161-164.

Neptune, R.R., Kautz, S.A., \& Zajac, F.E. (2001). Contributions of the individual ankle plantar flexors to support, forward progression and swing initiation during walking. Journal of biomechanics, 34, 1387-1398. doi: 10.1016/s0021-9290(01)00105-1

Pääsuke, M., Ereline, J., \& Gapeyeva, H. (2003). Age-related differences in knee extension rate of isometric force development and vertical jumping performance in women. Journal of Sports Medicine and Physical Fitness, 43, 453-458.

Pandy, M.G., \& Andriacchi, T.P. (2010) Muscle and joint function in human locomotion. Vol. 12 (pp. 401-433).

Pereira, M.P., \& Gonçalves, M. (2011). Muscular coactivation (CA) around the knee reduces power production in elderly women. Archives of Gerontology and Geriatrics, 52, 317-321. doi: 10.1016/j.archger.2010.04.024

Raikova, R.T., \& Prilutsky, B.I. (2001). Sensitivity of predicted muscle forces to parameters of the optimization-based human leg model revealed by analytical and numerical analyses. Journal of biomechanics, 34, 1243-1255.

Redl, C., Gfoehler, M., \& Pandy, M.G. (2007). Sensitivity of muscle force estimates to variations in muscle-tendon properties. Human Movement Science, 26, 306-319.

Scovil, C.Y., \& Ronsky, J.L. (2006). Sensitivity of a Hill-based muscle model to perturbations in model parameters. Journal of biomechanics, 39, 2055-2063.

Sipila, S., \& Suominen, H. (1991). Ultrasound imaging of the quadriceps muscle in elderly athletes and untrained men. Muscle Nerve, 14, 527-533. doi: 10.1002/mus.880140607

Thelen, D.G. (2003). Adjustment of muscle mechanics model parameters to simulate dynamic contractions in older adults. Journal of Biomechanical Engineering, 125, 70-77.

Tsaopoulos, D.E., Baltzopoulos, V., Richards, P.J., \& Maganaris, C.N. (2011). Mechanical correction of dynamometer moment for the effects of segment motion during isometric knee-extension tests. Journal of Applied Physiology, 111, 68-74. doi: 10.1152/ japplphysiol.00821.2010

Ward, S.R., Eng, C.M., Smallwood, L.H., \& Lieber, R.L. (2009). Are current measurements of lower extremity muscle architecture accurate? Clinical orthopaedics and related research, 467, 1074-1082.

Zajac, F.E. (1989). Muscle and tendon: properties, models, scaling, and application to biomechanics and motor control. Critical Review in Biomedical Engineering, 17, 359-411.

Zawadzki, J., Bober, T., \& Siemienski, A. (2010). Validity analysis of the Biodex System 3 dynamometer under static and isokinetic conditions. Acta Bioeng Biomech, 12(4), 25-32.

\section{Authors' note}

Guilherme Auler Brodt (http://lattes.cnpq.br/4124783671364967) is affiliated with the Health and Biology Sciences Center, University of Caxias do Sul, Brazil.

Jeam Marcel Geremia (http://lattes.cnpq.br/0077391619897733) is affiliated with Faculdade Sogipa de Educação Física and Universidade Federal do Rio Grande do Sul, Porto Alegre, Brazil.

Mônica de Oliveira Melo (http://lattes.cnpq.br/0993186688228552) is affiliated with the Health and Biology Sciences Center, Núcleo de Pesquisa em Ciências e Artes do Movimento Humano, University of Caxias do Sul, Brazil.

Marco Aurélio Vaz (http://lattes.cnpq.br/2093718148536940) and Jefferson Fagundes Loss (http://lattes.cnpq.br/6622799236125103) are affiliated with the Exercise Research Laboratory - Federal University of Rio Grande do Sul, Brazil. 


\section{Corresponding author}

Guilherme Auler Brodt

Travessa Jundiaí 2215, apartment 401, Higienópolis, Porto Alegre 90520-270, RS, Brazil.

E-mail address: guilhermebrodt@gmail.com

\section{Acknowledgement}

We would like to thank the Biomechanics and Kinesiology Research Group of the Federal University of Rio Grande do Sul for collecting and sharing the muscle architecture data. We would like to thank the University of Caxias do Sul for their support. CAPES and CNPQ funded this study.

Manuscript received on June 10, 2015

Manuscript accepted on September 21, 2015

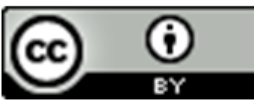

Motriz. The Journal of Physical Education. UNESP. Rio Claro, SP, Brazil - eISSN: 1980-6574 - under a license Creative Commons - Version 3.0 